\title{
Why Is WASID an Important Clinical Trial?
}

\author{
Robert G. Hart \\ Department of Medicine (Neurology), University of Texas Health Science Center, San Antonio, Tex., USA
}

Fifty years ago, coumarins (i.e. warfarin and other oral vitamin K antagonists) were first given for secondary prevention of ischemic stroke and were widely prescribed for this purpose during the subsequent decades despite the paucity of good evidence supporting their benefit, not unusual for neurological therapeutics of the era. More recently, it has been established that antiplatelet agents reduce subsequent stroke and other major vascular events by about $20 \%$ for patients with cerebral ischemia, a benefit that is not offset for most patients by a modestly increased risk of major bleeding [1]. When, if ever, should warfarin anticoagulation be given instead of antiplatelet therapy to patients with noncardioembolic brain ischemia?

To date, six randomized clinical trials involving 4,090 participants have compared aspirin in dosages of 30$1,300 \mathrm{mg} /$ day with oral anticoagulants in such patients [2, 3]. Individually and in aggregate, these trials demonstrated no advantage of oral anticoagulation over aspirin. The recent Warfarin-Aspirin Recurrent Stroke Study (WARSS) is the largest (2,206 participants) and most methodologically rigorous; it showed that warfarin, mean achieved INR $=1.9$, is not better and could be worse than aspirin $325 \mathrm{mg} /$ day for unselected patients with noncardioembolic brain ischemia [3, 4]. In another of these trials, a mean achieved INR of about 3 resulted in an intolerable rate of brain hemorrhage that caused early termination [5]. In short, for unselected elderly patients with noncardioembolic brain ischemia, an INR of 3 is too much and an INR of 2 is too little. At present, warfarin in any intensity should not be routinely used instead of antiplatelet therapy for secondary prevention of noncardioembolic brain ischemia, as there is no clear evidence favoring its use over the safer, more easily administered alternative.

In this issue, the Warfarin Aspirin Symptomatic Intracranial Disease (WASID) trial investigators report their trial design and initial experience [6]. Patients with TIA or minor ischemic stroke associated with arteriographically proven intracranial stenosis are randomly assigned to warfarin (target INR range 2-3) vs. aspirin $650 \mathrm{mg}$ twice daily in a double-blind design and followed for development of stroke or vascular death, the primary outcome. In all, 806 participants will be included. With recruitment over halfway completed, a discouragingly high false-positive rate for prediction of intracranial stenosis by noninvasive tests has been found. The relatively young mean age (63.5 years) probably reflects screening biases rather than the population prevalence of the disorder.

Will WASID add importantly to stroke prevention? Yes, without question. Several features make WASID unique among trials comparing warfarin with aspirin in noncardioembolic brain ischemia. The target INR of 2.5 in a double-blind design will test the most relevant intensity of anticoagulation in a scientifically rigorous manner.

\section{KARGER \\ Fax +41613061234 \\ E-Mail karger@karger.ch \\ www.karger.com

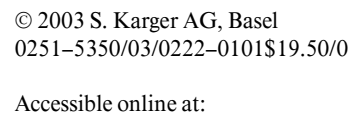

\footnotetext{
Robert G. Hart, MD

Department of Medicine (Neurology), University of Texas Health Science Center

7703 Floyd Curl Drive, MC 7883

San Antonio, TX 78229-3900 (USA)

Tel. +1 210617 5161, Fax +1 210567 4659, E-Mail hartr@uthscsa.edu
} 
The dwindling few who believe that high-dose aspirin offers additional protection for stroke prevention will be pleased with the dosage tested in WASID. Most importantly, WASID offers the only randomized comparison of warfarin with aspirin in high-risk patients with arteriographically proven occlusive cerebrovascular atherosclerosis. Consequently, the implications of WASID potentially extend beyond secondary prevention of the $10 \%$ of cerebral ischemia attributed to intracranial atherosclerosis. Subsets at particularly high risk of stroke will likely be identified by arteriographic data.

The importance of testing antithrombotic agents in well-defined etiological subgroups of ischemic stroke patients is dramatically illustrated by the very large reduction in stroke by warfarin over aspirin in atrial fibrillation patients [7] compared with trends favoring aspirin over warfarin for unselected patients with noncardioembolic brain ischemia. This disparity is seen in the substantially higher rates of anticoagulation-associated intracerebral hemorrhage in those with noncardioembolic ischemia [8]. Compared with patients with atrial fibrillation, warfarin in patients with intrinsic cerebrovascular disease is less efficacious and more dangerous. Ischemic stroke etiological subtypes do matter, for antithrombotic prophylaxis and probably for other interventions as well. The prevalence of leukoaraiosis detected by neuroimaging among WASID participants and its relationship to brain hemorrhage will be of great interest [9]. Intracerebral hemorrhage is exquisitely sensitive to blood pressure [10], and careful monitoring, control and reporting of blood pressure will be integral to understanding the results of WASID.

WASID promises to be a landmark clinical trial. It is an especially challenging trial to execute, requiring invasive arteriography and double-blind administration of anticoagulation during a prolonged follow-up. The WASID investigators and study participants will make important, unique contributions to the fight against stroke.

\section{References}

1 Antithrombotic Trialists' Collaboration: Collaborative meta-analysis of randomised trials of antiplatelet therapy for prevention of death, myocardial infarction, and stroke in high risk patients. BMJ 2002;324:71-86.

2 Algra A, De Schryver ELLM, van Gijn J, Kapelle LJ, Koudstaal PJ: Oral anticoagulants versus antiplatelet therapy for preventing further vascular events after transient ischaemic attack or minor stroke of presumed arterial origin (Cochrane review); in: Cochrane Library, Issue 4, 2002. Update Software.

3 Mohr JP, Thompson JLP, Lazar RM, Levin B, Sacco RL, Furie KL, Kistler JP, Albers GW, Pettigrew LC, Adams HP Jr, et al for the Warfarin-Aspirin Recurrent Stroke Study Group: A comparison of warfarin and aspirin for the prevention of recurrent ischemic stroke. N Engl J Med 2001;345:1444-1451.
4 Hankey GJ: Warfarin-Aspirin Recurrent Stroke Study (WARSS) trial: Is warfarin really a reasonable therapeutic alternative to aspirin for preventing recurrent noncardioembolic ischemic stroke? Stroke 2002;33:1723-1726.

5 Stroke Prevention in Reversible Ischemia Trial (SPIRIT) Study Group: A randomized trial of anticoagulants versus aspirin after cerebral ischemia of presumed arterial origin. Ann Neurol 1997;42:857-865.

6 Warfarin Aspirin Symptomatic Intracranial Disease (WASID) Trial Investigators: Design, progress and challenges of a double-blind trial of warfarin versus aspirin for symptomatic intracranial arterial stenosis. Neuroepidemiology 2003;22:106-117.
7 van Walraven C, Hart RG, Singer DE, Laupacis A, Connolly S, Petersen P, Koudstaal PJ, Chang Y, Hellemons B: Oral anticoagulants vs aspirin in nonvalvular atrial fibrillation: An individual patient meta-analysis. JAMA 2002 ; 288:2441-2448.

8 Gorter JW: Major bleeding during anticoagulation after cerebral ischemia: Patterns and risk factors. Stroke Prevention in Reversible Ischemia Trial (SPIRIT). European Atrial Fibrillation Trial (EAFT) study groups. Neurology 1999;53:1319-1327.

9 Smith EE, Rosand J, Knudsen KA, Hylek EM, Greenberg SM: Leukoaraiosis is associated with warfarin-related hemorrhage following ischemic stroke. Neurology 2002;59:193-197.

10 PROGRESS Collaborative Group: Randomised trial of a perindopril-based blood-pressure-lowering regimen among 6,105 individuals with previous stroke or transient ischaemic attack. Lancet 2001;358:1033-1041. 